\title{
Comparison of volume-controlled and pressure-controlled ventilation using a laryngeal mask airway during gynecological laparoscopy
}

\author{
Woo Jae Jeon, Sang Yun Cho, Mi Rang Bang, and So-Young Ko \\ Department of Anesthesiology and Pain Medicine, Guri Hospital, Hanyang University Collge of Medicine, Guri, Korea
}

Background: Several publications have reported the successful, safe use of Laryngeal Mask Airway (LMA)-Classic devices in patients undergoing laparoscopic surgery. However, there have been no studies that have examined the application of volume-controlled ventilation (VCV) or pressure-controlled ventilation (PCV) using a LMA during gynecological laparoscopy. The aim of this study is to compare how the VCV and PCV modes and using a LMA affect the pulmonary mechanics, the gas exchange and the cardiovascular responses in patients who are undergoing gynecological laparoscopy.

Methods: Sixty female patients were randomly allocated to one of two groups, (the VCV or PCV groups). In the VCV group, baseline ventilation of the lung was performed with volume-controlled ventilation and a tidal volume of $10 \mathrm{ml} / \mathrm{kg}$ ideal body weight (IBW). In the PCV group, baseline ventilation of the lung using pressure-controlled ventilation was initiated with a peak airway pressure that provided a tidal volume of $10 \mathrm{ml} / \mathrm{kg} \mathrm{IBW}$ and an upper limit of $35 \mathrm{cmH}_{2} \mathrm{O}$. The end-tidal $\mathrm{CO}_{2}$, the peak airway pressures $\left(\mathrm{P}_{\text {peak }}\right)$, the compliance, the airway resistance and the arterial oxygen saturation were recorded at T1: 5 minutes after insertion of the laryngeal airway, and at T2 and T3: 5 and 15 minutes, respectively, after $\mathrm{CO}_{2}$ insufflation.

Results: The $\mathrm{P}_{\text {peak }}$ at 5 minutes and 15 minutes after $\mathrm{CO}_{2}$ insufflation were significantly increased compared to the baseline values in both groups. Also, at 5 minutes and 15 minutes after $\mathrm{CO}_{2}$ insufflation, there were significant differences of the $\mathrm{P}_{\text {peak }}$ between the two groups. The compliance decreased in both groups after creating the pneumopertoneim $(\mathrm{P}<0.05)$.

Conclusions: Our results demonstrate that PCV may be an effective method of ventilation during gynecological laparoscopy, and it ensures oxygenation while minimizing the increases of the peak airway pressure after $\mathrm{CO}_{2}$ insufflation. (Korean J Anesthesiol 2011; 60: 167-172)

Key Words: Lapraroscopic surgery, LMA, Pressure-controlled ventilation, Volume-controlled ventilation.

Received: June 16, 2010. Revised: 1st, July 19, 2010; 2nd, September 10, 2010. Accepted: September 15, 2010.

Corresponding author: Sang Yun Cho, M.D., Department of Anesthesiology and Pain Medicine, Guri Hospital, Hanyang University Collge of Medicine, 249-1, Gyomoon-dong, Guri 471-701, Korea. Tel: 82-31-560-2390, Fax: 82-31-563-1731, E-mail: chosy@hanyang.ac.kr

(c) This is an open-access article distributed under the terms of the Creative Commons Attribution Non-Commercial License (http:// creativecommons.org/licenses/by-nc/3.0/), which permits unrestricted non-commercial use, distribution, and reproduction in any medium, provided the original work is properly cited. 


\section{Introduction}

Laparoscopic surgery is being increasingly used in many surgical procedures $[1,2]$. The cardiopulmonary physiology and the pathophysiology of pneumoperitoneum are now well understood [3]. An elevated intraabdominal pressure and abdominal expansion shifts the diaphragm upwards. Thus, as the intrathoracic pressure increases, the abdominal part of the chest wall become stiff and expansion of the lung is restricted. This is followed by a significant decrease in pulmonary dynamic compliance and an increase in the peak airway pressure $\left(\mathrm{P}_{\text {peak }}\right)[1,4]$. However, high airway pressures and decreased compliance can be associated with pulmonary barotrauma, which may manifest as immediate pneumothorax. In order to limit this increase in the $\mathrm{P}_{\text {peak }}$, the anesthesiologist can change the respiratory rate (RR) and the tidal volume, or they can change from volume-controlled ventilation (VCV) to pressure-controlled ventilation (PCV). PCV has been proposed as an alternative to VCV for intensive care unit patients with adult respiratory distress syndrome [5] and for obese patients to achieve adequate oxygenation and normocapnia $[6,7]$. PCV delivers the tidal volume faster than does VCV, and they have different gas distributions and a high and decelerating inspiratory inspiratory flow. These characteristics of PCV tend to compensate for any potential reduction in ventilation caused by a pressure limitation [8]. PCV is now frequently used in the operating room for the management of patients with an elevated $\mathrm{P}_{\text {peak }}$. Despite this widespread use, we still do not have a complete understanding of PCV's ventilator and hemodynamic effects $[2,6]$.

Several studies have reported the successful, safe use of the Laryngeal Mask Airway (LMA)-Classic devices in patients who are undergoing laparoscopic surgery [9-11]. Maltby et al. [9] demonstrated that the change in the degree of gastric distension with positive pressure during peritoneal insufflation was similar with using either a LMA or an endotracheal tube, and that the ventilator parameters (pulse oxygen saturation, endtidal $\mathrm{CO}_{2}$ tension and airway pressure) were acceptable using either a LMA or an endotracheal tube. Bapat and Verghese [12] confirmed that the incidence of regurgitation during laparoscopes with a LMA was extremely low. Several studies have shown that the $\mathrm{P}_{\text {peak }}$ is lower with PCV $[13,14]$. Bordes et al. [14] suggested that PCV is more efficient than VCV for controlled ventilation with a LMA. Gastric insufflations did not occur with PCV. However, there have been no studies that have explored the application of VCV or PCV and using a LMA during gynecological laparoscopy.

The aim of this study was to compare how the VC and PC modes could affect the pulmonary mechanics, the gas exchange and the cardiovascular responses in patients who are undergoing gynecological laparoscopy using a LMA.

\section{Materials and Methods}

After approval by the local ethics committee, 60 ASA physical status I or II female patients gave us their written informed consent to be included in this study. The patients with a history of gastric reflux, a history of allergy to any of the study drugs, suspected difficulty with their airway passages or those taking antiepileptic medication were excluded from the study.

The patients were randomly allocated to one of two groups (the VCV and PCV groups) by using computer-generated numbers. The anesthetic management and intraoperative care were standardized. Upon arrival in the operating room, routine monitoring was done and a Bispectral Index (BIS) (Aspect Medical Systems, USA) sensor was attached. We measured the baseline values of the systolic arterial pressure (SAP), the mean arterial blood pressure (MAP), the heart rate, the oxyhemoglobin saturation and the BIS. A $20 \mathrm{G}$ i.v. cannula was inserted, and anesthesia was induced with a targetcontrolled infusion (TCI) of remifentanil set at an initial effect site concentration of $2 \mathrm{ng} / \mathrm{ml}$. The infusion device was an Orchestra ${ }^{\circledR}$ Base Primea (Fresenius Kabi, France) and the PK was the Minto model [15], which adjusts for age, weight and gender. The device has an equilibration constant (Keo) of $0.595-0.007 \times($ age -40$) / \mathrm{min}$, and a simultaneous infusion of TCI $2 \%$ propofol was done using the PK parameters of Schnider et al. [16] set at an initial effect site concentration of $4-6 \mu \mathrm{g} / \mathrm{ml}$. One minute after administering $0.9 \mathrm{mg} /$ $\mathrm{kg}$ of IV rocuronium, the LMA-classic was inserted by one anesthesiologist (C.S.). Successful placement was confirmed by the presence of bilateral chest wall movement and the occurrence of a square wave trace on the capnograph during manual ventilation. Mechanical ventilation was done with an Avance (Datex-Ohmeda, WI, USA). Anesthesia was maintained with propofol and remifentanil in 50\% oxygen/air, and this was adjusted to keep the BIS values between 45 and 60 , and the remifentanil was TCI adjusted to maintain adequate analgesia. Throughout the study period, neuromuscular block was assured with the administration of rocuronium as evidenced by the lack of a train of four responses to neuromuscular stimulation. After completion of the surgery, the residual neuromuscular block was reversed with pyridostigmine $0.2 \mathrm{mg} / \mathrm{kg}$ and glycopyrrolate $0.008 \mathrm{mg} / \mathrm{kg}$.

Once a LMA insertion was achieved, the oropharyngeal cuff leak pressures were obtained by closing the expiratory valve of the anesthesia circuit with a fixed gas flow rate of $3 \mathrm{~L} / \mathrm{min}$ and noting the airway pressure at which equilibrium was reached.

In the VCV group, baseline ventilation of the lung was done with volume-controlled ventilation and a tidal volume of 10 
$\mathrm{ml} / \mathrm{kg}$ ideal body weight (IBW). The initial respiratory rate of 12 breaths per minute was adjusted during laparoscopy to maintain an end-tidal carbon dioxide pressure of 30-35 mmHg. Five minutes after LMA insertion and mechanical ventilation, the first blood samples were taken for blood gas analysis; the blood samples were taken from the radial artery and then peritoneal insufflation was initiated. The inspiratory to expiratory ratio was set at $1: 2$.

In the PCV group, baseline ventilation of the lung was done with pressure-controlled ventilation, and this was initiated with a peak airway pressure that provided a tidal volume of $10 \mathrm{ml} / \mathrm{kg}$ IBW with an upper limit of $35 \mathrm{cmH}_{2} \mathrm{O}$. Five minutes after LMA insertion and mechanical ventilation, a first blood was taken for blood gas analysis and peritoneal insufflation was initiated.

In both groups, a carbon dioxide pneumoperitoneum was induced with a maximal intraabdominal pressure of $15 \mathrm{mmHg}$, and the maximal allowed head-down Trendelenberg position was $15^{\circ}$. Then, the second blood gas analysis was done 15 minutes after peritoneal insufflation. In all the patients, the $\mathrm{FiO}_{2}$ was maintained at $50 \%$. The end-tidal $\mathrm{CO}_{2}$, the $\mathrm{P}_{\text {peak }}$, the leak pressure, the mean airway pressure, the compliance, the airway resistance and the arterial oxygen saturation were continuously monitored during the procedure and they recorded at T1: 5 minutes after insertion of the laryngeal airway, T2: 5 minutes after $\mathrm{CO}_{2}$ insufflation and T3: 15 minutes after $\mathrm{CO}_{2}$ insufflation. The $\mathrm{P}_{\text {peak }}$, the leak pressure, the mean airway pressure, the compliance and the airway resistance were measured by spirometry via an Avance (Datex-Ohmeda, WI, USA).

\section{Power analysis}

To estimate the group size, a pilot study was conducted in 20 patients from the VCV group. The standard deviation of the compliance in this group was $4.2 \mathrm{ml} / \mathrm{cmH}_{2} \mathrm{O}$. For our power calculation, we assumed an equal standard deviation for compliance in the PCV group. We wanted to be able to show a difference of $3.7 \mathrm{ml} / \mathrm{cmH}_{2} \mathrm{O}$ in compliance between the two groups. With an $\alpha=0.05$, two tailed and a power of $90 \%$, we

Table 1. Demographic Data

\begin{tabular}{lcc}
\hline & $\begin{array}{c}\text { Group VCV } \\
(\mathrm{n}=30)\end{array}$ & $\begin{array}{c}\text { Group PCV } \\
(\mathrm{n}=30)\end{array}$ \\
\hline Age (yr) & $45.5 \pm 10.5$ & $42.1 \pm 8.8$ \\
Weight (kg) & $59.9 \pm 8.4$ & $58.9 \pm 7.9$ \\
Height (cm) & $157.5 \pm 4.6$ & $156.8 \pm 5.1$ \\
OT (min) & $146.21 \pm 58.6$ & $123.2 \pm 64.5$ \\
AT (min) & $183.8 \pm 58.7$ & $158.3 \pm 68.0$ \\
\hline
\end{tabular}

Values are means \pm SDs. VCV: volume-controlled ventillation, PCV: pressure-controlled ventilation, OT: operating time, AT: anesthetic time. needed 30 patients per group. Hence, a total of 60 patients were included in this study.

\section{Statistical analysis}

The data is expressed as means \pm SDs or as categorical distributions. Statistical analysis was performed using the Statistical Package for Social Sciences software (SPSS 12.0 for windows; SPSS Inc, IL, USA) and SigmaStat (SIGMASTAT 3.1; Systat Software, INC., CA, USA). Between-group comparisons for the numerical data were analyzed with an unpaired t-test. When the normality test failed, the Mann-Whitney Rank Sum Test was used. The nonparametric data were analyzed by using the $\chi^{2}$ test and Fisher's exact test (when appropriate), and the parametric data was analyzed by using Kruskal-Wallis One Way Analysis of variance with a Dunn multiple comparison test for inter-group comparisons. P values $<0.05$ were regarded as statistically significant.

\section{Results}

Sixty patients were enrolled. The two groups were demographically similar (Table 1).

The lung mechanics are shown in Table 2. The peak airway pressures generated by a tidal volume of a $10 \mathrm{ml} / \mathrm{kg}$ IBW were not statistically different in both groups. The $\mathrm{P}_{\text {peak }} 5$ minutes and 15 minutes after $\mathrm{CO}_{2}$ insufflation were significantly increased compared to the baseline values in both groups $(\mathrm{P}<0.01)$. Also, at 5 minutes and 15 minutes after $\mathrm{CO}_{2}$ insufflation, there were significant differences of the $\mathrm{P}_{\text {peak }}$ between two groups $(\mathrm{P}<$ 0.05). There were no significant differences of the leak pressure between both groups and within the groups. Compliance

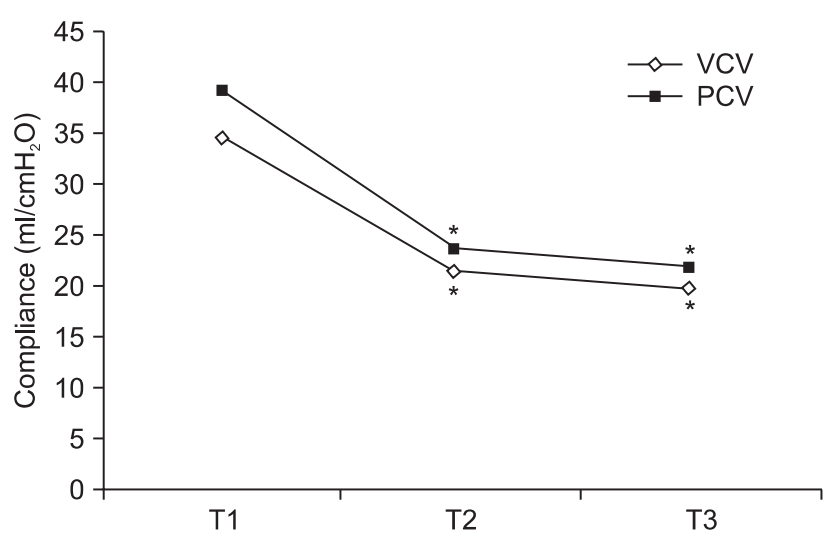

Fig. 1. Changes of compliance during anesthesia. T1: 5 minutes after insertion of the laryngeal airway, T2: 5 minutes after $\mathrm{CO}_{2}$ insufflation, T3: 15 minutes after $\mathrm{CO}_{2}$ insufflation, VCV: volumecontrolled ventillation, PCV: pressure-controlled ventilation. ${ }^{*} \mathrm{P}<$ 0.01 compared with the $\mathrm{T} 1$ value. 
Table 2. Lung Mechanics

\begin{tabular}{|c|c|c|c|c|c|c|}
\hline \multirow{2}{*}{$\begin{array}{c}\text { Time point } \\
\text { group }(n=30)\end{array}$} & \multicolumn{2}{|c|}{$\mathrm{T} 1$} & \multicolumn{2}{|c|}{$\mathrm{T} 2$} & \multicolumn{2}{|c|}{ T3 } \\
\hline & VCV & PCV & VCV & PCV & VCV & PCV \\
\hline Peak airway pressure $\left(\mathrm{cmH}_{2} \mathrm{O}\right)$ & $16.2 \pm 3.0$ & $14.8 \pm 2.1$ & $24.9 \pm 4.8^{*}$ & $22.8 \pm 2.9^{*, \dagger}$ & $27.4 \pm 4.7^{*}$ & $24.3 \pm 3.0^{*, \dagger}$ \\
\hline Leak pressure $\left(\mathrm{cmH}_{2} \mathrm{O}\right)$ & $25.0 \pm 5.2$ & $27.0 \pm 3.7$ & $26.9 \pm 5.8$ & $27.2 \pm 3.7$ & $27.0 \pm 5.0$ & $27.1 \pm 4.2$ \\
\hline Compliance $\left(\mathrm{ml} / \mathrm{cmH}_{2} \mathrm{O}\right)$ & $34.8 \pm 5.0$ & $39.3 \pm 5.9$ & $21.5 \pm 5.8^{*}$ & $23.8 \pm 3.9 *$ & $19.7 \pm 4.4^{*}$ & $22.0 \pm 2.6^{*}$ \\
\hline Airway resistance $\left(\mathrm{cmH}_{2} \mathrm{O} / \mathrm{L} / \mathrm{s}\right)$ & $7.9 \pm 1.8$ & $6.5 \pm 1.3$ & $10.4 \pm 3.3^{*}$ & $10.6 \pm 2.5^{*}$ & $10.6 \pm 2.5^{*}$ & $10.9 \pm 2.7^{*}$ \\
\hline Expiratory tidal volume (ml) & $552.5 \pm 72.7$ & $510.2 \pm 132.9$ & $523.3 \pm 93.2$ & $539.4 \pm 58.7$ & $535.4 \pm 58.7$ & $530.3 \pm 57.9$ \\
\hline
\end{tabular}

Values are means \pm SDs. T1: 5 minutes after insertion of the laryngeal airway, T2: 5 minutes after $\mathrm{CO}_{2}$ insufflation, T3: 15 minutes after $\mathrm{CO}_{2}$ insufflation, VCV: volume-controlled ventillation, PCV: pressure-controlled ventilation. $* \mathrm{P}<0.01$ compared with the $\mathrm{T} 1$ value, ${ }^{\dagger} \mathrm{P}<0.05$ compared with the VCV value.

Table 3. Data on Gas Exchange

\begin{tabular}{|c|c|c|c|c|}
\hline \multirow{2}{*}{$\begin{array}{c}\text { Time point } \\
\text { group }(n=30)\end{array}$} & \multicolumn{2}{|c|}{$\mathrm{T} 1$} & \multicolumn{2}{|c|}{ T3 } \\
\hline & VCV & PCV & VCV & PCV \\
\hline PH & $7.52 \pm 0.04$ & $7.52 \pm 0.02$ & $7.48 \pm 0.05^{*}$ & $7.48 \pm 0.03^{*}$ \\
\hline $\mathrm{PaO}_{2}$ & $256.5 \pm 88.4$ & $257.6 \pm 47.6$ & $205.6 \pm 52.2^{*}$ & $209.5 \pm 47.4^{*}$ \\
\hline $\mathrm{PaCO}_{2}$ & $28.0 \pm 3.6$ & $25.8 \pm 1.9^{\dagger}$ & $31.9 \pm 5.5^{*}$ & $28.3 \pm 2.0^{*, \dagger}$ \\
\hline $\mathrm{EtCO}_{2}$ & $29.6 \pm 2.6$ & $29.9 \pm 2.3$ & $30.5 \pm 3.3$ & $30.9 \pm 2.1$ \\
\hline
\end{tabular}

Data are means \pm SDs. T1: 5 minutes after insertion of the laryngeal airway, T3: 15 minutes after $\mathrm{CO}_{2}$ insufflation, VCV: volume-controlled ventillation, $\mathrm{PCV}$ : pressure-controlled ventilation, $\mathrm{PaO}_{2}$ : partial pressure of oxygen in the arterial blood, $\mathrm{PaCO}$ : partial pressure of carbon dioxide in the arterial blood, $\mathrm{EtCO}_{2}$ : end-tidal carbon dioxide. ${ }^{*} \mathrm{P}<0.01$ compared with the $\mathrm{T} 1$ value, ${ }^{\dagger} \mathrm{P}<0.05 \mathrm{compared}$ with the $\mathrm{VCV}$ value.

Table 4. Hemodynamic Responses at Different Time Points

\begin{tabular}{|c|c|c|c|c|c|c|}
\hline \multirow{2}{*}{$\begin{array}{c}\text { Time point } \\
\text { group }(n=30)\end{array}$} & \multicolumn{2}{|c|}{$\mathrm{T} 1$} & \multicolumn{2}{|c|}{$\mathrm{T} 2$} & \multicolumn{2}{|c|}{ T3 } \\
\hline & VCV & PCV & VCV & PCV & VCV & PCV \\
\hline SAP (mmHg) & $125.2 \pm 15.0$ & $125.4 \pm 16.6$ & $130.6 \pm 17.4$ & $134.1 \pm 17.0$ & $132.0 \pm 14.2$ & $127.0 \pm 15.0$ \\
\hline MAP (mmHg) & $97.1 \pm 10.9$ & $96.1 \pm 12.5$ & $101.1 \pm 12.8$ & $103.0 \pm 9.2$ & $101.4 \pm 10.5$ & $99.5 \pm 10.4$ \\
\hline $\mathrm{HR}(\mathrm{bpm})$ & $75.8 \pm 14.7$ & $74.4 \pm 13.0$ & $67.5 \pm 12.0$ & $69.7 \pm 11.1$ & $71.1 \pm 13.4$ & $70.4 \pm 10.2$ \\
\hline
\end{tabular}

Values are means \pm SDs. T1: 5 minutes after insertion of the laryngeal airway, T2: 5 minutes after $\mathrm{CO}_{2}$ insufflation, T3: 15 minutes after $\mathrm{CO}_{2}$ insufflation, VCV: volume-controlled ventillation, PCV: pressure-controlled ventilation, SAP: systolic arterial pressure, MAP: mean arterial pressure, HR: heart rate.

decreased in both groups after pneumopertoneim (Fig. 1). Airway resistance significantly increased in both groups after $\mathrm{CO}_{2}$ insufflation (Table 2).

The $\mathrm{pH}$ decreased and the arterial partial pressure of carbon dioxide increased in both groups after $\mathrm{CO}_{2}$ insufflation (Table 3). In the PCV group, the increase of the arterial partial pressure of carbon dioxide was lower compared to that of the VCV group $(\mathrm{P}<0.05)$. Comparison of the VCV and PCV modes did not reveal any significant differences in oxygenation. The end-tidal $\mathrm{CO}_{2}$ values did not differ between the groups. The end-tidal $\mathrm{CO}_{2} 15$ minutes after $\mathrm{CO}_{2}$ insufflation was also not significantly different between the two groups.

Pneumoperitoneum did not induce a significant increase in the SAP and MAP in both groups (Table 4), and there were also no significant differences between the groups. The heart rate was not significantly increased in both groups after $\mathrm{CO}_{2}$ insufflation.

\section{Discussion}

We have demonstrated that PCV is a rational method of ventilation during gynecological laparoscopy to ensure proper oxygenation while minimizing the increase of the peak airway pressure after $\mathrm{CO}_{2}$ insufflation.

Earlier studies have shown that the LMA-Classic can be successfully used to ventilate with adequate pulmonary ventilation during laparoscopic surgical procedures $[9,10,12]$. Galvin et al. [10] demonstrated that pressure-controlled ventilation using the LMA-Classic might be useful during pneumoperitoneum. However, they did not compare the effects of VCV and PCV.

PCV is an alternative mode of ventilation that is widely used in patients with severe respiratory failure [17]. PCV has been shown to improve arteial oxygenation and decrease the peak airway pressure because of its decelerating inspiratory flow. 
Uniform distribution of inspired gas with PCV is the major cause of better arterial oxygenation in patients with respiratory failure $[5,17]$. PCV is now frequently used in the operating room for the management of patients with an elevated $\mathrm{P}_{\text {peak }}$, despite an incomplete understanding of its ventilation and hemodynamic effects or its potential complications [2,17]. During one case of lung anesthesia, Tuğrul et al. [17] concluded that PCV appeared to be an alternative to VCV and it might be superior to VCV for patients with respiratory disease. However, Unzueta et al. [18] found that the use of PCV during one-lung ventilation did not lead to improved oxygenation compared with that of VCV for patients with good preoperative pulmonary function, but PCV did lead to a lower $\mathrm{P}_{\text {peak }}$. During laparoscopy, Balick-Weber et al. [2] found no advantage of PCV over VCV regarding the respiratory mechanics, gas exchange or the cardiac function, and specifically the risk of barotrauma was not decreased by PCV.

De Baerdemaeker et al. [6] demonstrated that VCV and PCV appeared to be equally suited ventilator techniques for laparoscopic procedures in morbidly obese patients, and the carbon dioxide elimination was more efficient when using VCV. They also found that this observation must be because of differences of minute ventilation, physiologic dead space or $\mathrm{CO}_{2}$ production. Endotracheal intubation was performed those previous studies.

In this study, we found that the increase of the arterial partial pressure of carbon dioxide in the PCV group was lower compared to that of the VCV group. This result may be because of the characteristics of PCV. For a given tidal volume, the inspiratory flow reaches much higher values with PCV than with the VCV mode. The alveoli with a short time constant may be initially over-inflated, but then a more homogenous distibution of the tidal volume in all the ventilated alveoli could follow. Therefore, the differences of the $\mathrm{PaCO}_{2}$ may be due to a better ventilation/perfusion ratio in the PCV group.

$\mathrm{CO}_{2}$ pneumoperitoneum induces significant hemodynamic changes: increases in heart rate, the arterial blood pressure and the systemic vascular resistance [1-3]. The hemodynamic effects in laparoscopy are predominantly due to hypercarbia and the increased intraabdominal pressure [3]. These effects are further influenced by the intraoperative position of the patient, the duration of the procedure, the rate of $\mathrm{CO}_{2}$ administration and the volume of gas used for insufflations, the age of the patient and the comorbid cardiopulmonary conditions $[3,19]$. We found that the SAP and MAP 15 minutes after $\mathrm{CO}_{2}$ insufflation were greater than the baseline values, but there were no significant differences, and the HR 15 minutes after pneumoperitoneum were not different from the baseline values.

In conclusion, we demonstrated that PCV using a LMA is a rational method of ventilation during gynecological laparoscopy to ensure proper oxygenation and to eliminate $\mathrm{CO}_{2}$ while minimizing the increases of the peak airway pressure after $\mathrm{CO}_{2}$ insufflation.

\section{References}

1. Koivusalo AM, Lindgren L. Effects of carbon dioxide pneumoperitoneum for laparoscopic cholecystectomy. Acta Anaesthesiol Scand 2000; 44: 834-41.

2. Balick-Weber CC, Nicolas P, Hedreville-Montout M, Blanchet P, Stéphan F. Respiratory and haemodynamic effects of volumecontrolled vs pressure-controlled ventilation during laparoscopy: a cross-over study with echocardiographic assessment. Br J Anaesth 2007; 99: 429-35.

3. Sharma KC, Brandstetter RD, Brensilver JM, Jung LD. Cardiopulmonary physiology and pathophysiology as a consequence of laparoscopic surgery. Chest 1996; 110: 810-5.

4. Hirvonen EA, Nuutinen LS, Kauko M. Ventilatory effects, blood gas changes, and oxygen consumption during laparoscopic hysterectomy. Anesth Analg 1995; 80: 961-6.

5. Prella M, Feihl F, Domenighetti G. Effects of short-term pressurecontrolled ventilation on gas exchange, airway pressures, and gas distribution in patients with acute lung injury/ARDS: comparison with volume-controlled ventilation. Chest 2002; 122: 1382-8.

6. De Baerdemaeker LE, Van der Herten C, Gillardin JM, Pattyn P, Mortier EP, Szegedi LL. Comparison of volume-controlled and pressure-controlled ventilation during laparoscopic gastric banding in morbidly obese patients. Obes Surg 2008; 18: 680-5.

7. Cadi P, Guenoun T, Journois D, Chevallier JM, Diehl JL, Safran D. Pressure-controlled ventilation improves oxygenation during laparoscopic obesity surgery compared with volume-controlled ventilation. Br J Anaesth 2008; 100: 709-16.

8. Davis K Jr, Branson RD, Campbell RS, Porembka DT. Comparison of volume control and pressure control ventilation: is flow waveform the difference? J Trauma 1996; 41: 808-14.

9. Maltby JR, Beriault MT, Watson NC, Fick GH. Gastric distension and ventilation during laparoscopic cholecystectomy: LMA-Classic vs. tracheal intubation. Can J Anaesth 2000; 47: 622-6.

10. Galvin EM, van Doorn M, Blazquez J, Ubben JF, Zijlstra FJ, Klein $\mathrm{J}$, et al. A randomized prospective study comparing the Cobra Perilaryngeal Airway and Laryngeal Mask Airway-Classic during controlled ventilation for gynecological laparoscopy. Anesth Analg 2007; 104: 102-5.

11. Verghese C, Brimacombe JR. Survey of laryngeal mask airway usage in 11,910 patients: safety and efficacy for conventional and nonconventional usage. Anesth Analg 1996; 82: 129-33.

12. Bapat PP, Verghese C. Laryngeal mask airway and the incidence of regurgitation during gynecological laparoscopies. Anesth Analg 1997; 85: 139-43.

13. Natalini G, Facchetti P, Dicembrini MA, Lanza G, Rosano A, Bernardini A. Pressure controlled versus volume controlled ventilation with laryngeal mask airway. J Clin Anesth 2001; 13: 436-9.

14. Bordes M, Semjen F, Degryse C, Bourgain JL, Cros AM. Pressurecontrolled ventilation is superior to volume-controlled ventilation with a laryngeal mask airway in children. Acta Anaesthesiol Scand 2007; 51: 82-5. 
15. Minto CF, Schnider TW, Egan TD, Youngs E, Lemmens HJ, Gambus $\mathrm{PL}$, et al. Influence of age and gender on the pharmacokinetics and pharmacodynamics of remifentanil. I. Model development. Anesthesiology 1997; 86: 10-23.

16. Schnider TW, Minto CF, Gambus PL, Andresen C, Goodale DB, Shafer SL, et al. The influence of method of administration and covariates on the pharmacokinetics of propofol in adult volunteers. Anesthesiology 1998; 88: 1170-82.

17. Tuğrul M, Camci E, Karadeniz H, Sentürk M, Pembeci K, Akpir
K. Comparison of volume controlled with pressure controlled ventilation during one-lung anaesthesia. Br J Anaesth 1997; 79: 306 10.

18. Unzueta MC, Casas JI, Moral MV. Pressure-controlled versus volume-controlled ventilation during one-lung ventilation for thoracic surgery. Anesth Analg 2007; 104: 1029-33.

19. Joris JL, Noirot DP, Legrand MJ, Jacquet NJ, Lamy ML. Hemodynamic changes during laparoscopic cholecystectomy. Anesth Analg 1993; 76: 1067-71. 